\title{
Analisis Ketergantungan China-Sri Lanka dalam Proyek Pembangunan Pelabuhan Hambantota Tahun 2007-2017
}

\section{Vivi Ariesta Nurjayanti}

Program Studi Ilmu Hubungan Internasional, Universitas Muhammadiyah Malang, Jawa Timur Indonesia

Email: viviariestaaa@gmail.com

Diserahkan: 16 Juni 2020 | Diterima: 30 Juni 2020

\begin{abstract}
Abtract
The purpose of this research is that the reader can find out the problem of Sri Lanka's dependence on China in the Hambantota Port development project which ultimately ended up as a debt trap. In this research authors used qualitative research methods. And from the results of research that has been done, it is found that basically the cooperation carried out by China and Sri Lanka is a collaboration between hegemon countries and third world countries. Debt trap diplomacy itself has close links with other Chinese policies, namely the Belt and Road Initiative, this policy focuses on infrastructure development which includes the construction of railroad networks, the construction of roads to ports located in the territories of other countries and has a strategic position and will good impact for the achievement of Chinese interests in realizing the "new Silk Road". Sri Lanka proposed cooperation to build the port of Hambantota with the aim of helping to improve Sri Lanka's economy. Cooperation that is expected to have a positive impact on Sri Lanka actually brings disaster, because it leads to a debt trap that makes Sri Lanka must hand over the port of Hambantota to the China's government.
\end{abstract}

Keywords: Debt, Trap, Belt, Road, Initiative, Hambantota, China-Sri Lanka.

\begin{abstract}
Abstrak
Tujuan dari dibuatnya artikel ini adalah agar pembaca bisa mengetahui permasalahan ketergantungan Sri Lanka terhadap China dalam proyek pembangunan Pelabuhan Hambantota di Sri Lanka yang pada akhirnya berujung sebagai debt trap. Dalam penelitian ini penulis menggunakan metode penelitian kualitatif. Hasil penelitian yang telah dilakukan didapati bahwa pada dasarnya kerjasama yang dilakukan oleh China dan Sri Lanka merupakan kerjasama antara negara hegemon dengan negara dunia ketiga. Debt trap diplomacy sendiri memiliki kaitan yang cukup erat dengan kebijakan Tiongkok lainnya yakni Belt and Road Initiative, kebijakan ini berfokus pada pembangunan infrastruktur yang meliputi pembangunan jaringan rel perkeretaapian, pembangunan jalan hingga pelabuhan yang berlokasi di teritorial negara lain serta memiliki posisi strategis dan akan berdampak baik bagi pencapaian kepentingan Tiongkok dalam mewujudkan "Jalur Sutra baru". Sri Lanka mengajukan kerjasama untuk membangun pelabuhan Hambantota dengan tujuan untuk membantu meningkatkan perekonomian Sri Lanka. Kerjasama yang diharapkan bisa membawa dampak positif bagi Sri Lanka justru membawa petaka, karena berujung pada terjadinya debt trap yang membuat Sri Lanka harus menyerahkan pelabuhan Hambantota kepada pemerintah China.
\end{abstract}

Kata Kunci: Hutang, Perangkap, Belt, Road, Inisiatif, Hambantota, Cina-Sri Lanka.

\section{PENDAHULUAN}

Sri Lanka, memiliki nama resmi Republik Sosialis Demokratik Sri
Lanka. Negara ini terletak di pesisir tenggara India. Sampai pada tahun 
1972, Sri Lanka dikenal dengan nama Ceylon, nama ini diberikan oleh kolonialisme Inggris. Pada 4 Februari 1948 Sri Lanka mendapatkan kemerdekaannya dan juga negara ini anggota dari negara-negara persemakmuran. Ekspor sektor pertanian menjadi tulang punggung dari negara ini. Sektor lainnya berupa produk garmen, rempah-rempah, tekstil, hasil laut, karet, kelapa dan juga produk olahan dari laut dan kelapa. Terdapat juga berbagai jenis batu mulia seperti, berlian, zamrud, giok, biduri laut, akik, safir, mirah delima, opal dan sebagainya. Industri utama dari negara ini ialah grafit yang di mana sebagian besar diekspor ke Jepang. Serta adanya industri keramik dan juga porselen yang berkembang di negara ini (Profil Sri Lanka, 2020).

Negara ini juga mempunyai banyak pantai yang indah, sehingga di kembangkan oleh pihak lokal atau internasional yang mengelolanya. Selain itu juga terdapat adanya perkebunan teh ataupun situs bersejarah dan objek wisata. Namun potensi yang dimiliki negara ini, belum dikembangkan secara optimal, hal ini dikarenakan keterbatasan berbagai sumber-sumber. Sehingga negara ini dapat bekerjasama dengan negara lain, atapun negara lain dapat memberikan bantuannya terhadap Sri Lanka (Profil Sri Lanka, 2020).
Hubungan China dengan Sri Lanka tidak berbeda dengan hubungan yang dilakukan China kepada negara lain. Khususnya kerjasama kepada negara dunia ketiga atau negara berkembang lainnya. Secara umum negara berkembang membutuhkan bantuan dan pinjaman dana dari negara maju dalam mendukung pembangunan di dalam negaranya. Hal ini membuat Sri Lanka sebagai negara dengan berbagai masalah kesejahteraan sosial dan perdagangan memilih untuk melakukan kerjasama ekonomi perdagangan dengan China (Amalia, 2017).

Salah satu kebijakan kerjasama China dalam Belt Road Initiativenya ialah mengenai aspek pembangunan pelabuhan. Sri Lanka membutuhkan pelabuhan sebagai bentuk dari penggerak ekonomi negara itu. Dengan adanya pelabuhan tersebut, maka secara otomatis akan memudahkan Sri Lanka dalam melakukan ekspor dan impor. Namun perlu dipahami pula bahwa China memberikan inisiasi seperti itu dikarenakan pelabuhan yang dibuat di Sri Lanka merupakan modal China dalam mengembangan dan memajukan perekonomian negara itu. Adanya pelabuhan tersebut tidak hanya mewakili komoditi Sri Lanka namun juga sebagai jalur singgah kapal-kapal untuk mengangkut dan meyalurkan komoditi ekspor-impor ke 
China ditambah dengan fakta bahwa pelabuhan tersebut juga merupakan bagian dari Jalur maritim perdagangan China dalam One Belt One Road Initiative. Bentuk kerjasama seperti ini merupakan bentuk penguatan kepentingan nasional sebuah negara yang lebih kaya yang bersanding dengan negara-negara berkembang dibawahnya (Putera et.al).

Perlu diketahui pula bahwasanya Sri Lanka tidak berhasil mendapatkan manfaat yang seharusnya dari kebijakan inisiasi dari China tersebut. Sebab kerjasama seharunya memberikan manfaat lebih kepada negara penerima bukan melebihi negara donor. Pembangunan pelabuhan tersebut malah menimbulkan ketergantungan kepada Sri Lanka berdasarkan perjanjian yang mereka sepakati. Maka dari itu pembuatan pelabuhan tersebut menjadi utang dan masalah baru negara di Asia Selatan tersebut. Mengenai China sebagai negara donatur diberbagai negara, bahwa dalam bantuan yang dilakukan oleh China terdapat adanya kepentingan kebijakan yang besar bagi kepentingan nasional China. Terutama pada saat ini perekonomian China berkembang dengan sangat pesat, dan juga hal inilah yang menjadi negara lain ingin bekerja sama dengan China, untuk meningkatkan perekonomian masing- masing negara yang bekerja sama (Amalia R, 2017).

Namun mengenai bantuan yang diberikan China terhadap Sri Lanka ini, dalam berita CNN kebijakan Belt and Road yang dicetuskan oleh China menyebabkan banyaknya utang di berbagai negara. Berita tersebut tertulis, proyek infrastruktur perdagangan yang menjadi kebijakan dari the belt and road ini berupa pembangunan rel kereta api, pelabuhan maupun jalan yang berada di seluruh dunia. Untuk melakukan pembangunan tersebut, maka dananya berasal dari Beijing bernilai miliaran dolar. Kebijakan dari China ini dengan berbagai negara di dunia melebihi US $\$ 5$ triliun, dalam hal perdagangan dan investasi melebihi US\$60 miliar (Kebijakan Belt and Road China).

Pertumbuhan ekonominya juga yang menjadikan China memiliki kekuatan di dunia internasional. Melihat besarnya perkembangan China dalam perekonomiannya, maka semakin banyaknya negara yang ingin bekerja sama dengan China atau meminta bantuannya. Salah satu contohnya ialah China memberikan pinjam tanpa syarat kepada Sri Lanka, namun pastinya adanya kepentingan nasional yang dijalankan. Mengenai hal ini disebabkan oleh ketidak mampuan Sri Lanka untuk mengembalikan pinjaman sehingga diserahkannya pelabuhan Sri Lanka kepada China. 
Hal ini menimbulkan banyak kekhawatiran dari negara-negara tetangga, dikarenakan dengan China memegang pelabuhan di Sri Lanka maka kekuatan angkatan laut China di Samudera Hindia akan semakin menguat. Hal inilah yang menjadi strategi China untuk meningkatkan kekuatan negara di level internasional.

\section{METODE}

Dalam menulis Artikel ini, penulis menggunakan jenis penelitian eksplanatif. Artikel ini membatasi fokus penelitian pada kasus "Kerjasama China-Sri Lanka dalam Proyek Pembangunan Pelabuhan Hambantota di Sri Lanka" yang terjadi pada tahun 2007-2017. Karena dalam rentang tahun tersebut, kasus tentang pelabuhan Hambantota dari awal terjalinnya kerjasama hingga akhirnya berakhir menjadi debt trap mencuat ke publik.

Dalam artikel ini pula penulis menggunakan teknik internet searching dan teknik analisa data kualitatif, yaitu menggambarkan isi dari isu atau topic yang diangkat berdasarkan pada fakta yang ada kemudian disusun menjadi sebuah hasil penelitian, tetapi tidak berdasarkan akurasi statistik yang mengandung angka-angka (Ulber, S. (2012).

\section{TEORI}

\section{Teori Ketergantungan}

Ketergantungan merupakan keadaan di mana kondisi perekonomian suatu negara tertentu (negara berkembang) dipengaruhi oleh perkembangan dan ekspansi yang dilakukan oleh negara lain (negara pusat). Di mana ada negara yang berperan sebagai penerima pengaruh dan negara yang berperan untuk mempengaruhi kondisi perekonomian negara lain. Dikatakan ketergantungan apabila negara yang dominan bisa memperluas pengaruh ekonominya di negara lain, sedangkan negara penerima hanya bisa menerima akibat dari pengaruh tersebut. Negara penerima bantuan disebut sebagai negara satelit sedangkan negara yang berperan sebagai pemberi bantuan disebut sebagai negara pusat.

Dari teori yang dikemukakan oleh Andre Gunder Frank kerjasama yang bersifat ketergantungan ini memiliki hubungan erat dengan hal politik dan ekonomi. Khususnya hubungan antara pemilik modal asing dengan golongan tertentu di negara satelit. Dalam menganalisa kasus China-Sri Lanka ini penulis menggunakan pendekatan ketergantungan finansial-industrial di mana dalam pendekatan ini ketergantungan bisa terjadi karena negara satelit memiliki sumberdaya 
yang terbatas, dan kerjasama ini terjadi tanpa ada paksaan dari pihak negara pusat. Negara yang menjadi pemberi bantuan bisa menanamkan modal ke negara satelit, bantuan tersebut bisa berupa bantuan langsung, kerjasama dengan pemerintah negara satelit (Budiman, 1995).

China's debt trap diplomacy dapat dikategorikan ke dalam kosakata baru dalam lingkup hubungan internasional, hal ini dikemukakan oleh seorang berkebangsaan India yang merupakan seorang akademisi bernama Brahma Chelanney yang merujuk kepada sebuah strategi yang menempatkan suatu negara pada kondisi yang cukup rumit, suatu negara akan memberikan pinjaman secara berlebih kepada negara lain dengan tujuan agar dapat memperoleh konsesi ekonomi atau politik. Ketika negara bersangkutan mengalami kegagalan dalam proses pengembalian utang. Ditambah faktor lain yakni pada awal tahun 2017 ketika China sedang mendapat sorotan akan perekonomiannya oleh beberapa negara lain (Setyanti \& Mugasejati, 2018). Debt trap diplomacy yang ada saat ini memiliki kaitan yang cukup erat dengan kebijakan Tiongkok lainnya yakni Belt and Road Initiative, kebijakan ini berfokus pada pembangunan infrastruktur-infrastruktur yang meliputi pembangunan jaringan rel perkeretaapian, pembangunan jalan hingga pelabuhan yang berlokasi di teritorial negara lain serta memiliki posisi strategis dan akan berdampak baik bagi pencapaian kepentingan Tiongkok dalam mewujudkan "Jalur Sutra baru."

Gambar 1. Rute China's Belt \& Road Initiative

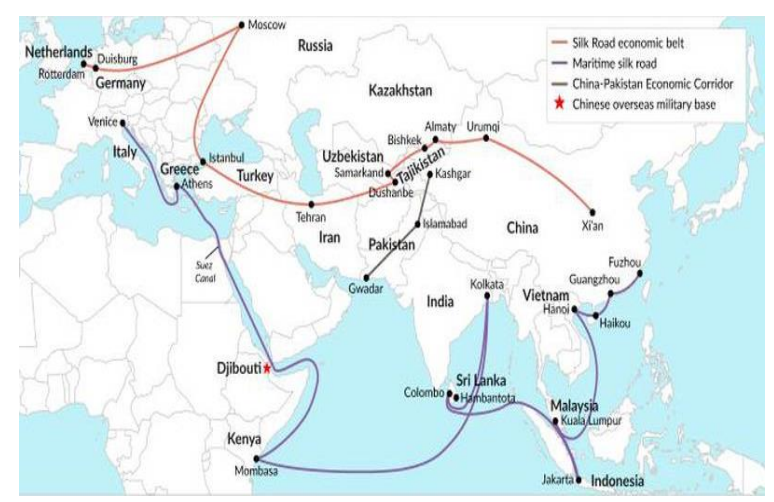

Kebijakan "Jalur Sutra Baru" sendiri muncul pada saat masa kepemimpinan Presiden Xi Jinping pada tahun 2013, lalu pada lima tahun kemudian tepatnya pada tahun 2017, $\mathrm{Xi}$ Jinping sebagai penggagas dari ide kebijakan ini harus mempertahankan apa yang telah beliau kemukakan karena seiring berjalannya waktu banyak pula muncul spekulasispekulasi dari pihak lain yang menganggap bahwa kebijakan ini akan menimbulkan kekhawatiran Tiongkok akan menggiring negara-negara yang tidak memiliki kemampuan dalam membayar utang akan terjebak di dalamnya. Tiongkokpun akhirnya bereaksi dalam menanggapi hal tersebut, dalam sebuah jumpa pers yang diadakan harian, Hua Chungyi selaku juru bicara Kementrian Luar 
Negeri China menyatakan bahwa tidak benar bahwa mereka (China) dengan sengaja memberikan tekanan atau beban kepada negara yang menjadi mitranya. Ditambah lagi dalam pertemuan itu juga terlontar sebuah statement yang mengatakan bahwa "Sangat tidak masuk akal memuji dana dari negara Barat sebagai langkah bagus dan apik, sementara dana dari China disebut jahat dan suatu jebakan". Pinjaman yang China berikan memiliki nilai yang setara dengan kendaraan konstruksi layaknya traktor, pengapalan batu bara, jasa rekayasa dan hal-hal serupa.

Kemudian mereka meminta bayaran pengambalian berupa uang. Dari pihak IMF, mereka juga merasa khawatir akan masalah utang yang terjadi nantinya serta mereka mengharapkan transparansi yang lebih baik dari pihak kreditur, terlebih Standard \& Poor's mengatakan bahwa apa yang dilakukan Tiongkok ini merupakan konsesi jangka panjang yang mana akan melibatkan satu perusahaan Tiongkok dalam menjalankan fasilitas ini hingga 20 sampai 30 tahun ke depan kemudian membagi keuntungnya dengan mitra mereka atau pemerintah local (Setyanti \& Mugasejati, 2018).

Sebenarnya debt trap ini tidaklah hadir sendiri dalam model ekonomi yang dapat dikatakan sebagai trap atau jebakan itu sendiri, ia memiliki dua teman lainnya yakni consumption trap dan liquidity trap, namun pada pembahasan ini kita akan berfokus kepada debt trap itu sendiri. Debt trap lebih merujuk kepada bentuk utang yang memiliki konsekuensi sistematis dan berkembang dalam konteks utang. Pihak kreditur sebagai pemberi pinjaman dapat berasal dari pihak swasta maupun non swasta. Hal yang acap kali melatar-belakangi seseorang atau sebuah negara melakukan peminjaman uang atau berhutang adalah faktor kebutuhan ataupun ketidaksetaraan, ketidaksetaraan dalam hal apa? Ketidaksetaraan di sini mungkin berasal dari kurang meratanya kesejahteraan masyarakat sehingga negara menjadikan utang sebagai instrumen pendukung yang dilakukan karena negara hendak melakukan belanja guna mendukung pembangunan dan pengembangan yang nantinya akan berdampak luas pada kesejahteraan masyarakat. Di sisi lain faktor kebutuhan lain dan juga tingginya nilai konsumtif suatu entitas juga dapat mempengaruhi (Sanchez \& Roelants, 2011).

Berhutang adalah suatu hal yang lumrah, berhutang juga akan menutupi kekurangan yang ada pada suatu rencana pembangunan yang mungkin tersendat karena permasalahan pendanaan yang kurang memadai. Pertanyaan yang muncul kemudian adalah apakah kekayaan sebuah negara 
tidak dapat menutupi kebutuhannya? Kita dapat mengambil contoh sebuah negara seperti Indonesia, dengan kekayaan sumber daya alam yang melimpah lalu letak geografisnya yang cukup baik dalam konteks perekonomian. Indonesia tercatat memiliki utang luar negeri yang cukup tinggi sehingga menimbulkan rasa khawatir pada masyarakatnya tentang kemampuan Indonesia dalam melunasi utang tersebut. Jumlah utang luar negeri Indonesia sebenarnya meskipun tinggi, masih masuk ke dalam kategori wajar karena Indonesia menempati posisi no 2 setelah Brunei ditambah lagi apabila melihat rasio antara PDB dan jumlah utang luar negeri Indonesia, PDB Indonesia sendiri masih mengalami pertumbuhan. Rasio utang luar negeri yang wajar adalah tidak boleh melebihi $60 \%$ dari PDB negaranya, semakin kecil presentasenya maka berarti semakin baik kemampuan negara dalam melunasi hutang tersebut (Clarica, 2020). Adapun dampak negatif yang dimunculkan adalah ketika suatu negara memiliki rasio yang tidak sesuai dengan batas aman presentase dari jumlah utangnya melebihi dari $60 \%$ persen PDB negara itu sendiri.

\section{HASIL DAN PEMBAHASAN}

China debt trap merupakan sebuah pandangan skeptik dari bangsa-bangsa barat yang berniat memojokkan China dalam perang dagang. Pandangan yang diberikan oleh bangsa barat yang berniat untuk memojokkan China dalam perang dagang ini merupakan suatu upaya untuk mengalahkan China dalam perang dagang tersebut. Dalam hal perang dagang sendiri China sudah memiliki upaya untuk membuat caranya sendiri yaitu dengan cara membangun proyek OBOR (One Belt One Road) yang merupakan salah satu upaya untuk membangun jalur sutra baru di dunia ini. Proyek OBOR merupakan salah satu proyek yang jalur perlintasannya melewati wilayah Indonesia dan juga melewati wilayah Sri Lanka. Sri Lanka adalah sebuah negara di Benua Asia Selatan yang berada tepat di selatan Republik India. Dengan penempatan daerah yang tepat yaitu berada di Selatan India maka posisi tersebut sangat strategis karena India merupakan salah satu negara yang memiliki tingkat konsumtif yang sangat tinggi. Hal ini juga berlaku dengan penempatan salah satu titik transit dari proyek OBOR di Singapura yang merupakan salah satu daerah yang kiranya berada di 3 negara sekaligus yaitu Indonesia, Singapura, dan juga Malaysia. Ketiga negara ini pun merupakan negara yang memiliki tingkat konsumtif yang tinggi (Var \& Po, 2017). 


\section{Awal Mula Sri Lanka Masuk China Debt Trap}

Bila merujuk kepada kata diplomacy yang ada di dalam kata "China debt trap diplomacy" maka kita akan menemukan bahwa Hubungan yang terjalin di antara Tiongkok dengan negara peminjam seperti negaranegara di Afrika maupun negaranegara di Asia sudah terjalin jauh sebelum Xi Jinping memiliki keinginan untuk mengaktifkan "Jalur Sutra Baru" dengan negara yang berada di Kawasan Asia, Khususnya Sri Lanka sudah terjadi sejak adanya Jalur Sutra pada abad 200 SM. Hal ini dapat dibuktikan dengan beberapa kajian serta penggalian arkeologis di beberapa daerah di Sri Lanka yang menemukan beberapa barang mulai dari koin China hingga potongan kain Romawi sehingga terlihat bahwa Sri Lanka pada masa itu telah menjadi tempat pertukaran komoditas yang sangat strategis dan menimbulkan upaya untuk menghidupkan Kembali Jalur Sutra Kuno (Perera, 2016).

Hubungan diplomatik yang terjalin pada masa selanjutnya di antara China dan Sri Lanka dimulai ketika kehadiran kedutaan besar China di Sri Lanka pada tahun 1957 yang tepatnya berlokasi di Kolombo dan juga kedutaan besar Sri Lanka yang berlokasi di Beijing.
Pada dasarnya memang hubungan antar negara pada umunya akan menuntun pada bentuk Kerjasama. Kerjasama tersebut bertujuan agar tercapainya tujuan bersama, hal tersebut berlaku pula pada kondisi yang terjadi pada China dan Sri Lanka. China menjadi investor besar bagi Sri Lanka, sejalan dengan pengembangan serta pembangunan infrastruktur yang bertujuan agar dapat memajukan Sri Lanka, dibutuhkan sokongan ekonomi yang besar dan kuat. Oleh karena itu China lah yang memiliki hal tersebut, namun di sisi lain sebagai sebuah negara, tentunya China memiliki tujuan pribadinya sendiri. Seperti yang telah dipaparkan di atas bahwa China ingin menghidupkan kembali Jalur Sutra Kuno serta menciptakan Maritime Silk Road Initiative maka hal inilah yang menjadikan kehadiran Sri Lanka menjadi penting hal tersebut dikarenakan letak pelabuhan yang dimilikinya sangat strategis dan bernilai ekonomis yang cukup tinggi (Perera, 2016).

Awalnya jalur Hambantonta ini merupakan salah satu jalur yang lumayan sibuk di wilayahnya. Kemudian Mr. Rajapaksa terpilih pada pemilu tahun 2015, dan berkeinginan untuk membentuk sebuah pelabuhan di jalur ini, untuk membangun sebuah pelabuhan dibutuhkan uang yang cukup besar untuk membangunnya. 
Oleh karena itu China menawarkan bantuan untuk membangun pelabuhan yang diinginkan oleh Mr. Rajapaksa dengan cara China menawarkan pinjaman. Kemudian Sri Lanka tidak dapat membayarkan pinjaman dari China ini.

Pinjaman yang tidak bisa dibayarkan-pun akhirnya mencapai ujungnya, pada hal ini adalah masamasa tenggat atau pembayaran dari hutang Sri Lanka ke China tersebut. Tenggat itu pun memaksa Sri Lanka untuk membayarkan hutangnya. Akan tetapi, Sri Lanka tidak dapat membayar hutangnya. Pada akhirnya China mengambil alih pelabuhan Hambantonta ini untuk 99 Tahun lamanya pada desember tahun 2015. Hal ini juga disebabkan karena ketidakmampuan Mr. Rajapaksa sebagai perdana menteri untuk membuat kebijakan yang dapat mengurangi beban dari hutang pelabuhan ini. Tidak hanya Pelabuhannya saja yang diambil alih oleh China, tetapi juga area Pelabuhan tersebut. Area yang lumayan luas untuk dijadikan sebagai sumber atau tempat untuk berinvestasi sebesar mungkin (Behuria, 2018).

Keuntungan yang didapat dari China dalam pengambilalihan Pelabuhan Hambantota ini juga cukup banyak dan cukup baik dalam investasi mereka. Pelabuhan Hambantota merupakan sebuah pelabuhan yang terletak di kota Hambantota, Srilanka.
Dibuka pada tahun 2010. Pelabuhan yang sekarang disewakan oleh China ini akan menjadi salah satu dari banyak investasi China yang akan sukses nantinya, karena pelabuhan ini terletak di tempat yang strategis yang terletak berhadapan langsung dengan samudra Hindia.

\section{Tujuan dan Latar Belakang Srilanka Melakukan Kerjasama Untuk Membangun Hambantota}

Sri Lanka sebagai salah satu negara yang pertama kali mengakui Republik Rakyat China merupakan salah satu negara yang memiliki hubungan yang sangat baik dan juga memiliki hubungan ramah dengan China. Tujuan dari pembangunan dari pelabuhan Hambantota ini sendiri karena kota Hambantota memiliki sumber daya alam yang cukup banyak dan nantinya akan bisa membuat pertumbuhan investasi kedua negara ini akan berkembang dengan sangat baik pada awalnya. Akan tetapi karena hutang dari Sri Lanka yang sudah ada sebelum dan sesudah pelabuhan Hambantota di bangun, Srilanka tidak dapat mencukupi total hutang yang diberikan oleh China. Latar belakang dari kerjasama kedua negara ini adalah dikarenakan kedua negara memiliki hubungan yang sangat baik jadi tidak heran lagi kalau China dan Sri Lanka sangat yakin untuk menjalani 
kerjasama di Hambantota (Perera, 2016).

\section{Gambar 2. Sri Lankan Debt Stock}

Sri Lankan Debt Stock by Lender (2017)

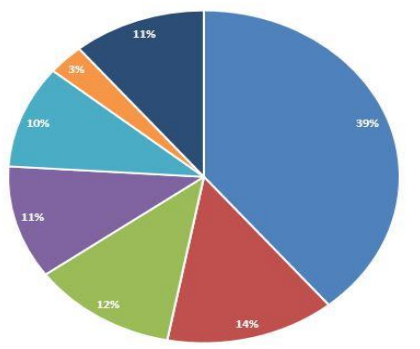

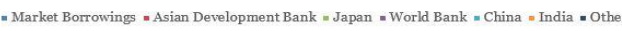

Sumber:

https://thediplomat.com/2019/05/is-srilanka-really-a-victim-of-chinas-debt-trap/

\section{Analisis Kerjasama Antara Sri Lanka dan China di Pelabuhan Hambantota}

Berdasarkan

teori

ketergantungan menjelaskan tentang hubungan erat dalam hal politik dan ekonomi. Khusunya hubungan antara pemilik modal asing dengan golongan tertentu di negara satelit. Menurut Dos Santos teori ketergantungan memiliki tiga bentuk ketergantungan (Kasnawi, M. T., \& Ramli, A. T. 2015), yaitu, (1) ketergantungan Kolonial;

ketergantungan finansial - industrial; dan (3) ketergantungan teknologis industrial.

$$
\text { Dalam konteks ini }
$$

menggunakan bentuk yang kedua yaitu ketergantungan Finansial - Industrial. Ketergantungan Finansial - Industrial adalah ketergantungan tetapi tidak ada unsur politik di dalamnya, ketergantungan mereka hanya berada dalam sektor finansial. Contohnya hanya seperti kerjasama ekonomi antara negara yang bekerja sama. Kerjasama antar Sri Lanka dengan China.

Kerjasama yang dilakukan oleh Sri Lanka - China merupakan kerjasama yang hanya ada di sektor ekonomi saja. Kedua negara ini sudah mulai melakukan kerjasama ekonomi sejak lama seperti yang ada di kotakota lain di Kolombo. Mereka melakukan kerjasama mulai dari pembangunan jalan sampai dengan pembangunan Bandar udara. Kali ini kedua negara ini membuat kerjasama di kota Hambantota untuk membangun sebuah Pelabuhan (Moramudali, 2019).

Kerjasama pembangunan pelabuhan di kota hambantota sudah dimulai sejak tahun 2007. Kerjasama yang dilakukan dengan China ini masih dibiayai sebagian proyeknya oleh Hong Kong - Based China Merchants Ports dan Otoritas Pelabuhan Srilanka.

Pembayaran pokok dan Bunga untuk pinjaman saat itu hanya $1,5 \%$ dari kewajiban pembayaran hutang luar negeri Sri Lanka (Sautman, B., \& Hairong, Y. 2019). Dan pada saat itu juga China memegang sekitar $9-15 \%$ dari hutang luar negeri Sri Lanka. 
Hal ini tentu berdampak sangat luas terhadap ekonomi Sri Lanka terhadap penyewaan Pelabuhan Hambantota. Srilanka terpaksa harus menyewakan pelabuhan Hambantota ini kepada China selama 99 tahun dan juga kurang lebih 130.000 hektar lahan di sekitar wilayah pelabuhan Hambantota ini.

\section{Analisis Ketergantungan Srilanka Kepada China dalam Pembangunan Pelabuhan Hambantonta}

Seperti yang sudah dijelaskan dalam analisis kerjasama Sri Lanka dan China dalam pembangunan pelabuhan Hambantonta, Sri Lanka jelas memiliki ketergantungan kepada China yaitu dalam sector keuangan. Hal ini juga disebabkan oleh keterlibatan China dalam meredakan konflik yang ada di Sri Lanka, yaitu konflik etnis. Konflik yang terjadi di Sri Lanka ini membuat Sri Lanka menjadi seperti "memiliki hutang budi" kepada China. Oleh sebab itu Sri Lanka memperbolehkan China untuk menanamkan Investasi yang lebih banyak.

Kerjasama yang dilakukan oleh Sri Lanka dan China inipun akhirnya menghasilkan ketergantungan Sri Lanka terhadap China yang pada akhirnya membuat Sri Lanka harus terpaksa menyewakan pelabuhan Hambantota selama 99 tahun.
Ketergantungan Sri Lanka terhadap China dalam hal keuangan disebabkan oleh kekurangan dalam segi moneter terhadap pembangunan fasilitas-fasilitas ekonomi seperti jalan raya, bandar udara, dan pelabuhan untuk menambahkan pemasukkan bagi Sri Lanka. Maka dari hal ini Sri Lanka perlu untuk meminjam dalam segi finansial kepada negara yang mereka anggap baik dari awal yaitu China. Seperti yang sudah dijelaskan di atas, China sudah membantu Sri lanka dalam pembangunan fasilitas-fasilitas seperti ini sebelumnya. Akan tetapi Sri Lanka memerlukan bantuan finansial lagi untuk membangun pelabuhan Hambantota.

\section{KESIMPULAN}

China membangun sebuah proyek yaitu OBOR (One Belt One Road) merupakan salah satu upaya untuk membangun Jalur Sutra Baru di dunia ini. Tujuan dari adanya proyek ini adalah bagaimana caranya agar wilayah China dapat terkoneksi dengan wilayah-wilayah di luar China yang strategis, entah itu melalui darat maupun lautan. Proyek OBOR ini sendiri salah satunya melewati wilayah Sri Lanka. Sri Lanka adalah sebuah negara di benua Asia Selatan menjadi sangat strategis dalam pandangan China untuk membangun posisi China sebagai mitra dagang terbesar. Hubungan kedua negara ini juga telah 
berlangsung sejak beberapa abad silam, dalam bidang perdagangan. Perjanjian Bilateral yang Sri Lanka lakukan dengan negara tetangganya juga melahirkan penawaran suatu peluang untuk terjalinnya kerjasama perdagangan dan investasi dalam pasar industrialisasi.

Sri Lanka awalnya membutuhkan uang untuk pembangunan pelabuhan Hambantota yang awalnya untuk membangun ekonominya yang mulai pasang surut. Hambantota sendiri memiliki sumber daya alam yang cukup banyak dan nantinya akan bisa membuat pertumbuhan investasi kedua negara ini akan berkembang dengan sangat baik. Pelabuhan Hambantota telah mendapatkan investasi dari Cina sebesar 2 miliar dollar Amerika Serikat dalam rangka pengembangan pembangunan proyek Pelabuhan tersebut. Pinjaman yang diberikan oleh pihak China tersebut nampaknya tidak melalui studi serta pertimbangan yang cukup layak serta mendalam terkait opsi dan langkah pembayaran ke depannya. Ketidakmampuan Sri Lanka dalam mengatasi hal ini dapat terlihat dari kendala yang terdapat dalam pembiayaan perawatan pelabuhan yang terbilang besar serta kemampuan mereka dalam pembayaran bunga yang berujung pada terciptanya peluang mereka masuk kedalam "Perangkap Hutang" yang sangat serius. Pada akhirnya China mengambil alih pelabuhan Hambantonta ini untuk 99 tahun lamanya pada Desember tahun 2015.

\section{REFERENSI}

Amalia, R. (2016). Kebijakan Politik Luar Negeri Republik. Rakyat China di Kawasan Asia Selatan Dan Dampaknya Dibidang Politik Dan Militer. Skripsi. Fakultas Ilmu Sosial dan Ilmu Politik: Universitas Hassanuddin.

Bajo, C.Z. \& Roelants, B. (2011) Capital and The Debt Trap-Learning From Cooperatives In The Global Crisis. United Kingdom: Palgrave Macmillan.

BBC Asia. (2019) Mahinda Rajapaksa: Sri Lanka's Long-Time Leader Back in Seat of Power (Online). Available at: https://www.bbc.com/news/worldasia-24918281 (Accessed: 1 May 2020).

Behuria, A. K. (2018) "How Sri Lanka Walked into a Debt Trap, and the Way Out." Strategic Analysis, 42(2), pp. 168178. Available at: https://www.tandfonline.com/doi/abs /10.1080/09700161.2018.1439327?jour nalCode $=$ rsan20 (Accessed: 1 May 2020).

Brautigam, D. (2019) “Is China's Development Diplomacy in Horn of Africa Transforming into Debt-Trap Diplomacy? An Evaluation", Area Development and Policy, 5(1). Available at: https://www.researchgate.net/publicati on/337816614_A_critical_look_at_Chi nese_'debttrap_diplomacy'_the_rise_of_a_meme. (Accessed: 1 May 2020).

Budiman, A. (1995). Teori Pembangunan Dunia Ketiga. Jakarta: Gramedia Pustaka Utama.

Chatzky, A. \& McBridge, J. (2020) Massive Belt and Road Initiative (Online). Available at: 
https://www.cfr.org/backgrounder/chi nas-massive-belt-and-road-initiative (Accessed: 26 April 2020).

CNN Indonesia. (2018) Kebijakan Belt and Road China Sebabkan Utang (Online). Available at: https://www.cnnindonesia.com/ekono $\mathrm{mi} / 20180902164934-92-$

326974/kebijakan-belt-and-road-chinasebabkan-utang-besar (Accessed: 26 April 2020).

Fernanda, C. (2018) Kenapa Pemerintab Membutubkan Utang Luar Negeri? (Online). Available at: https://www.kompasiana.com/claricaf /5cf0e93b18ffee7f2b10987b/kenapapemerintah-membutuhkan-utang-luarnegeri (Accessed: 1 May 2020).

Kasnawi, M. T., \& Ramli, A. T. (2015) Pembangunan Masyarakat Desa dan Kota (Online). Available at: http://repository.ut.ac.id/4281/1/IPE M4542-M1.pdf (Accessed: 6 May 2020).

KEMLU RI. (t.t) Profil Sri Lanka (Online). Available at: https://kemlu.go.id/colombo/id/pa ges/sri-lanka/1913/etc-menu (Accessed: 26 April 2020).

Moramudali, U. (2019) Is Srilanka Really a Victim of China's Debt Trap'? (Online). Available at: https://thediplomat.com/2019/05/issri-lanka-really-a-victim-of-chinas-debttrap/ (Accessed: 6 May 2020).

Nurjannah. (2020) Kerja Sama Pembangunan Infrastruktur Sri Langka dengan Tiongkok (Online). Available at: https://www.kompasiana.com/nurjann ah789/5e290a89d541df2b983ae5b2/ke rjasama-pembangunan-infrastruktur-srilangka-dengan-tiongkok-studi-kasuslepasnya-pelabuhanhambatota?page $=$ all (Accessed: 1 May 2020).
Perera, N. (2016) “China’s One Belt One Road Initiative: Implications for Sri Lanka", Education, 8(28). Available at: http://www.ips.lk/images/docs/news/ ips_media_pdf/2016/June \%202016/T he\%20Island_23June2016.pdf.

(Accessed: 29 April 2020).

Putera, I.G.N.A.P., Fasisaka, I., \& Prameswari, A. A. A. I. (2019) "Kepentingan Tiongkok Dalam Akuisisi Pelabuhan Hambantota Sri Lanka", Jurnal Hubungan Internasional, 1(1). Available at: https://ojs.unud.ac.id/index.php/hi /article/view/47631 (Accessed: 26 April 2020).

Sautman, B., \& Hairong, Y. (2019) The Truth About Sri Lanka's Hambantota Port, Chinese 'Debt Traps' and 'Asset Seizures (Online). Available at: https://www.scmp.com/comment/insi ght-opinion/article/3008799/truthabout-sri-lankas-hambantota-portchinese-debt-traps (Accessed: 6 May 2020).

Setyanti, W. \& Mugasejati, N. P. (2018) China's Debt-Trap Diplomacy" Di Era Xi Jinping Studi Kasus:'Kekalahan'sri Lanka Dalam Proyek Hambantota. Disertasi. Yogyakarta: Fisipol Universitas Gadjah Mada.

Ulber, S. (2012) Metode Penelitian Sosial. Bandung: Refika Aditama.

Var, V., \& Po, S. (2017) Cambodia, Sri Lanka and the China Debt Trap (Online).

Available at: https://bandapost.org/wpcontent/uploads/pdf/Dec $\% 20$ Cambod ia $\% 20$ and $\% 20$ Sri $\% 20$ Lanka $\% 20$ on $\% 20$ China's\%20debt\%20trap.pdf (Accessed: 1 May 2020). 